\title{
The Influence of Tensile Strength Difference with Variable Gravel Sizes on the Hydraulic Fracture Propagation in the Conglomerate Reservoir
}

\author{
Junnian Chen (iD \\ Exploration \& Development Research Institute of Liaohe Oilfield Company, Panjin 124010, China \\ Correspondence should be addressed to Junnian Chen; junnian3@163.com
}

Received 14 September 2021; Revised 12 January 2022; Accepted 18 January 2022; Published 17 February 2022

Academic Editor: Bao Jia

Copyright (c) 2022 Junnian Chen. This is an open access article distributed under the Creative Commons Attribution License, which permits unrestricted use, distribution, and reproduction in any medium, provided the original work is properly cited.

\begin{abstract}
Conglomerate reservoir is a representative reservoir of unconventional oil and gas resources, and hydraulic fracturing is also used to increase its production. However, the tensile strength of conglomerates with different sizes is various, which has an important impact on the hydraulic fracture propagation in the conglomerate reservoir. To study the tensile strength difference caused by the size of conglomerate gravel, some Brazilian splitting tests were conducted. To find the influence of tensile strength difference on the hydraulic fracture propagation, some true triaxial hydraulic fracturing experiments for layered formations were carried out. The concept of the fracture element in conglomerate formations was proposed. The results showed the following: (i) the tensile strength of conglomerate rock decreased with the increase of the gravel size, and the average tensile strengths of specimens with gravel diameters of $2.0-6.0 \mathrm{~mm}$ and $6.0-20.0 \mathrm{~mm}$ were $65.5 \%$ and $43.6 \%$ of that with $0.1-2.0 \mathrm{~mm}$ diameter, respectively; (ii) hydraulic fractures easily deflected at the interface of fine-grained conglomerate and medium-grained conglomerate; (iii) hydraulic fractures were prone to propagate to the layers with larger gravel sizes, and the smaller the gravel size, the lower the penetration probability. It is helpful to increase the understanding of the hydraulic fracture propagation under different gravel sizes in the conglomerate reservoir, and it can provide a reference for well distribution and hydraulic fracturing design.
\end{abstract}

\section{Introduction}

Driven by the economic development and world's energy demand, the need for unconventional resource development is gradually growing [1-8], especially shale oil and gas and unconventional oil and gas [9-11]. The conglomerate reservoir is a representative unconventional reservoir formed by rapid deposition near sources [12-14], with the characteristics of low permeability [15], large lithological changes, and strong heterogeneity $[16,17]$. However, the difference in tensile strength with variable gravel sizes and the distribution characteristics increase the difficulty in well designing and understanding the hydraulic fractures propagation directions [18].

The grain size was one of the most important parameters affecting the mechanical properties of rocks [19]. Some researchers studied the relationship between gravel size and rock strength. Hugman [20] established an inverse relationship between the rock strength (including the wield stress) and the mean grain size in carbonate rock. Olsson's study [21] showed that the rock strength was inverse with the square root of the grain size for marble. Yu [22] found that grain size resulted in different stress concentrations within a rock; the bigger the grain size was, the stronger the stress concentration was, and the lower the rock strength was. Lakirouhani [23] concluded that there was a significant positive correlation between grain size and tensile strength. Therefore, the grain size affected the rock mechanical properties.

From a meso point of view, the gravel in conglomerate reservoirs was discrete [24], and the gravel size always affected the damage evolution process $[25,26]$, which in turn influenced the macroscopic mechanical properties [25] and the fracturing mode [27] of a rock. In terms of the influence 
mechanism, previous research indicated that the stress distribution was affected by gravel structure $[12,28-30]$ and internal structure strength $[24,31,32]$ and then altered the mechanical properties of conglomerate rock [33] and fracturing behavior [34]. However, during the rock sample failure process, the minimum element (fracture element) and the rigidity of the conglomerate specimen need to be further discussed.

With the same in-situ stress, the difference in rock mechanical parameters affected the hydraulic fracture propagation [35-40]. The tensile strength of rock always influenced hydraulic fractures propagation characteristics [41-43], including the height, width, and surface roughness of hydraulic fractures. The fracture surface roughness and the fracture complicity affected the flow resistance, affecting the proppant transport and distribution [36]. For conglomerate reservoirs, similar to previous studies on hydraulic fracturing, researchers analyzed the in-situ stress difference $[41,44]$, fracturing fluid viscosity $[5,44]$, injection rate $[5,41,44]$, and rock heterogeneity $[41,44-48]$ on the influence of the shape of the hydraulic fractures. Besides, some studies showed that, due to the gravel size [42, 49], mineral content $[43,50]$, and cohesive strength $[45,51-53]$ differences in the conglomerate formations, the hydraulic fractures formed in the fine-grained conglomerate formations were relatively straight, while for the large-size gravel in conglomerate reservoirs, the hydraulic fractures always deflected along with the gravel interface or generated branch fractures [37, 38], and the fracture surfaces were distorted [42]. However, the gravel sizes in a conglomerate specimen were similar in the previous research. In the underground conglomerate reservoirs, the finegrained conglomerate and medium-grained conglomerate formations are often distributed in layers. The propagation of hydraulic fracture in layered conglomerate formations has not been researched yet.

In this study, to find the influence of the gravel size on the hydraulic fracture propagation in a layered conglomerate reservoir, some Brazilian split experiments on specimens with different gravel sizes were conducted firstly, and the tensile strength was obtained. The concept of the fracture element in conglomerate was proposed. Some true triaxial hydraulic fracturing experiments for layered formations were conducted, and the influence of tensile strength difference on hydraulic propagation was analyzed. It is helpful for understanding the hydraulic fracture propagation under different gravel sizes in the conglomerate reservoir, and it can provide a reference for the well distribution and hydraulic fracturing design.

\section{Experimental Methods and Steps}

During the hydraulic fracturing process, the fracture initiation and propagation behavior are closely related to the rock tensile strength. To study the propagation of hydraulic fractures in the layered reservoir with different gravel sizes, some Brazilian split experiments were conducted to get the tensile strength of conglomerate rocks with three gravel sizes. Then, the true triaxial hydraulic fracturing experiments were conducted to study the hydraulic fractures propagation characteristics.
2.1. Brazilian Specimens and Experimental Procedures. The gravel reservoirs are often distributed adjacent or interlaced with sandstone reservoirs. There are some transition zones between gravel layers with different gravel sizes in conglomerate formations. However, the size of the transition zone is generally several times the size of the standard Brazilian specimen. So, it is not suitable to measure the tensile strength from the transition zone directly in the laboratory. Instead, all specimens were cored from near layers (natural conglomerate formations in Liaohe, Liaoning Province, China) with different sizes of gravels. They were cored from one oil well, with similar depths. All samples were processed into standard size according to ISRM test standards [54, 55], and the specific dimensions of all specimens are shown in Table 1. According to the classification criteria of conglomerate recommended by Friedman [13], the rock can be divided into fine-grained conglomerate $(2.0-6.0 \mathrm{~mm})$, medium-grained conglomerate $(6.0-20.0 \mathrm{~mm})$, coarse conglomerate $(20.0-200.0 \mathrm{~mm})$, and large conglomerate $(>200.0 \mathrm{~mm})$ concerning the gravel size. In this paper, the fine-grained conglomerate and mediumgrained conglomerate were studied, and the Brazilian specimens with different gravel sizes are shown in Figure 1.

Through the Brazilian tests, the tensile strength of specimens with different gravel sizes was obtained. As shown in Figure 1, MTS rock mechanical parameters testing system was used. Firstly, the specimen was placed in the splitting fixture. At the initial stage, the sample was precompressed at a displacement rate of $1.0 \mathrm{~mm} / \mathrm{min}$ to $0.2 \mathrm{kN}$. Then, the displacement rate was set to $0.02 \mathrm{~mm} / \mathrm{min}$, until the specimen failure. During the loading process, the load and time were recorded. Finally, referring to (1) in the ISRM test standard $[54,55]$, the tensile strength of specimens with different gravel sizes was calculated.

$$
\sigma_{t}=\frac{2 P_{\max }}{\pi D B},
$$

where $\sigma_{t}$ is the tensile strength; $P_{\max }$ is the maximum load; $D$ is the diameter of the specimen; and $B$ is the thickness of the specimen.

\subsection{Hydraulic Fracturing Samples and Experimental} Procedures. If the tensile strength of conglomerate with variable sizes is different, there will be an important impact on the propagation of hydraulic fractures. To study the tensile strength difference caused by the size of conglomerate gravel and its effect on the hydraulic fracture propagation, some hydraulic fracturing tests were conducted on manual layered samples. Because the natural layered conglomerate rock was difficult to obtain, the specimens for hydraulic fracturing were manual rocks. The gravel sizes in the real conglomerate formation were mainly $2.0-6.0 \mathrm{~mm}$ and $6.0-20.0 \mathrm{~mm}$, which was similar to the fine-grained conglomerate and medium-grained conglomerate. From the lithological analysis, it was found that the weight ratio of gravel in a conglomerate sample was nearly $60 \%$. The specimen dimension was $30.0 \mathrm{~cm} \times 30.0 \mathrm{~cm} \times 30.0 \mathrm{~cm}$. The specimens were well mixed by the cement, quartz sand, and 
TABle 1: Specimen size of different grain sizes.

\begin{tabular}{lccc}
\hline No. & Gravel size $(\mathrm{mm})$ & Diameter $(\mathrm{mm})$ & Thickness $(\mathrm{mm})$ \\
\hline $1-1$ & & 25.02 & 11.62 \\
$1-2$ & $0.1-2.0$ & 25.00 & 12.40 \\
$1-3$ & & 24.96 & 11.62 \\
$1-4$ & & 25.04 & 12.46 \\
\hline $2-1$ & $2.0-6.0$ & 24.96 & 15.74 \\
$2-2$ & & 25.05 & 17.70 \\
$2-3$ & & 25.04 & 15.10 \\
$2-4$ & & 25.01 & 13.12 \\
\hline $3-1$ & & 25.03 & 14.32 \\
$3-2$ & & 25.02 & 13.20 \\
$3-3$ & & 25.05 & 15.86 \\
$3-4$ & & 25.00 & 12.42 \\
\hline
\end{tabular}

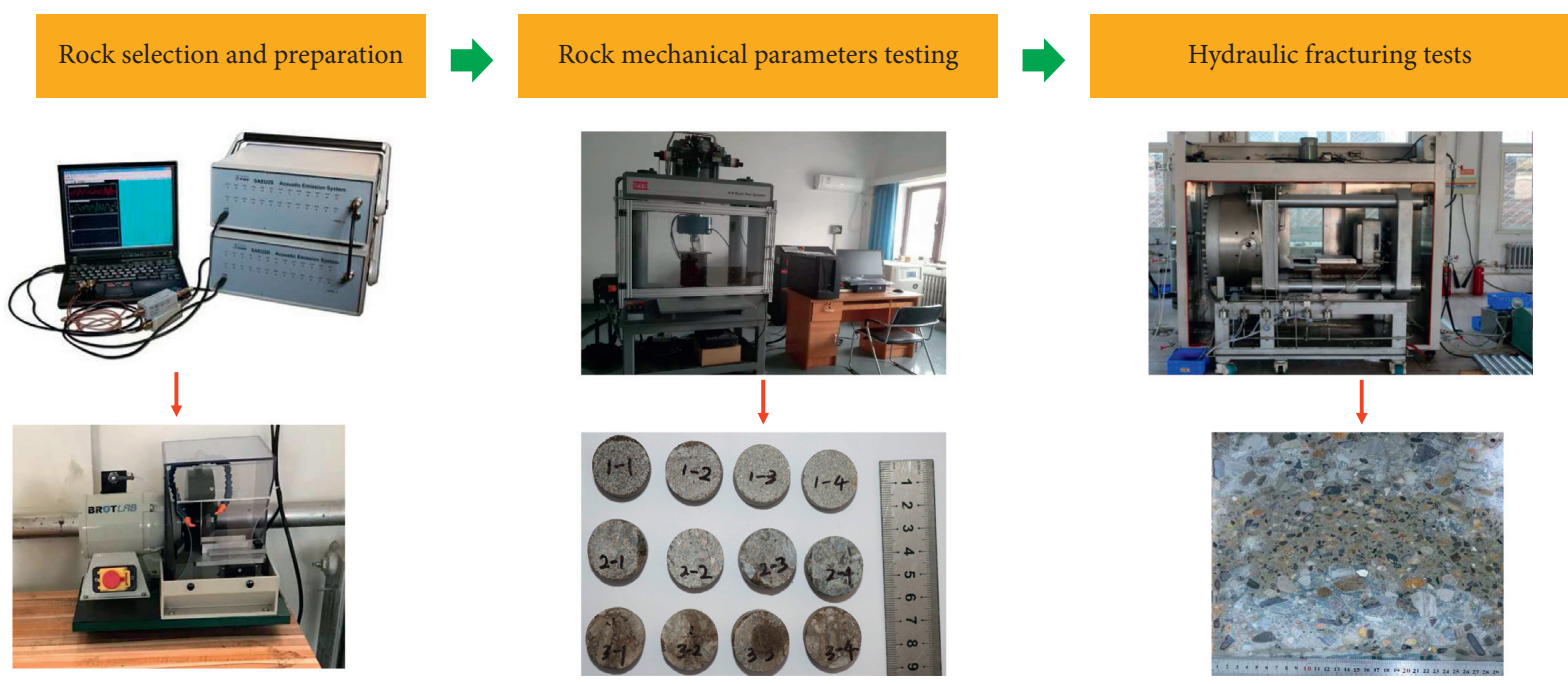

FIgURE 1: Experimental procedures and testing systems.

gravel, at the weight ratio of $1: 1: 2.5$. When a specimen was prefabricated, the gravels of the same size were mixed with cement firstly. Then, it was sprayed into three layers according to the gravel size. The specific layer types of all specimens are shown in Table 2, and the thickness of each layer was $10 \mathrm{~cm}$. The cross section of the specimen is shown in Figure 1. To make the gravel and cement in the specimen completely cemented, the prefabricated specimen was cured for 21 days.

As shown in Figure 1, a true triaxial hydraulic fracturing testing machine independently developed by the China University of Petroleum (Beijing) was used for hydraulic fracturing experiments. When performing hydraulic fracturing, the specimen was placed on the platform of the true triaxial hydraulic fracturing machine firstly. Then, the confining pressures along three directions were added according to Table 2 . Finally, the fracturing fluid was injected into the specimen at the corresponding rate until the specimen fractured eventually. During the injection process, the injection pressure and injection time were well recorded.

\section{Results and Discussion}

3.1. Tensile Strength Decreased with the Increase of the Gravel Size. The tensile strength of specimens with different gravel sizes is shown in Figure 2. It was found the tensile strength decreased with the increase of the gravel diameter. The average tensile strength of specimens with $2.0-6.0 \mathrm{~mm}$ and $6.0-20.0 \mathrm{~mm}$ diameter was $46.6 \%$ and $68.4 \%$ of that for a specimen with $0.1-2.0 \mathrm{~mm}$ diameter, respectively.

Hydraulic fracture propagation was closely related to the rock tensile strength. In conglomerate reservoirs, there were two common forms of hydraulic fracture when it encountered the gravel: perforating and winding the gravel [36]. The hydraulic fracturing mechanisms were different in the two forms. When fractures winded the gravel, it needed to overcome the cohesive strength of the intergranular cement. However, when fractures penetrated the gravel, it needed to overcome the tensile strength of the gravel itself and the cohesive strength of the cement between gravels. The difference between the two forms was mainly in the tensile strength of gravel. 
TABLE 2: Experimental parameters of layered conglomerate hydraulic fracturing.

\begin{tabular}{lccc}
\hline No. & Layer characteristic & Stress $(\mathrm{MPa})$ & Injection \\
\hline $1^{\#}$ & A-B rate $(\mathrm{ml} / \mathrm{min})$ \\
$2^{\#}$ & A-B-A & $30-16-10$ & 6 \\
$3^{\#}$ & B-A-B & $30-16-10$ & 6 \\
$4^{\#}$ & B-A-B & $30-16-10$ & 6 \\
\hline
\end{tabular}

Note. A represents $6.0-20.0 \mathrm{~mm}$ layer and B represents $2.0-6.0 \mathrm{~mm}$ layer.

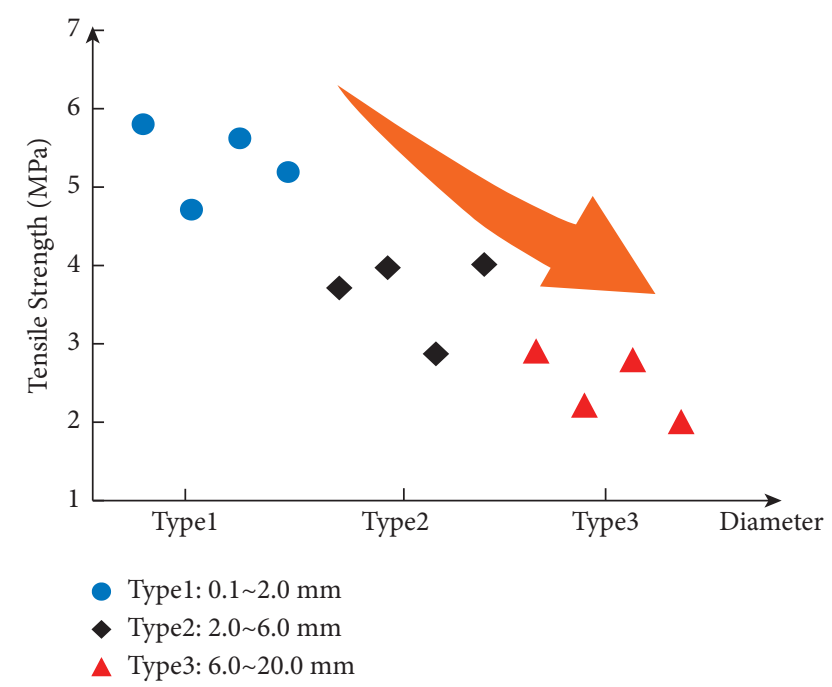

Figure 2: Tensile strength with different grain sizes.

The typical tensile stress-displacement curves of specimens at the central point with different grain sizes are shown in Figure 3. Before the peak load, the curve was divided into three stages: compaction stage, elastic deformation stage, and instability failure stage. The formation process of conglomerate reservoirs led to different internal structures of the specimens, which ultimately determined the differences in the loading curves. Regarding the geological origin of the reservoir, the formation process of conglomerate reservoirs concluded with the weathering of rocks, the splitting of gravels, and the sedimentation process. The cement between the gravels mainly contained detrital minerals such as clay, quartz, and feldspar. Mineral distribution characteristics were various, and there were great differences in the specimens with different gravel sizes.

With the increase of the gravel size, the dividing limit of the first and second stages became obvious in the loading curve, and the dividing limit in the second and third stages was gradually indistinct. In this paper, the fracture element of the conglomerate specimen was proposed, and it was used to compare the difference in the fracturing process caused by the gravel size. Like the concept of the representative elementary volume (REV), it was defined as the volume range for which all geometrical characteristics are single-valued functions of the location of that point and time only [56-59]. The fracture element in the conglomerate sample was defined to be the minimum element to describe the rock failure process, including all geometrical characteristics, such as mineral composition, microfracture, and gravel size. In detail, the concept of fracture element was illustrated from three aspects:

(1) As for the geometrical component of the fracture element, the fracture element contained the gravel in front of the fracture, the cement near the gravel, and the adjacent gravels. For the adjacent gravels, due to the difference in gravel size of the medium-grained and fine-grained conglomerate specimen, the number of gravels involved in the element was various for them. The number of the adjacent gravels in fine-grained specimens would be more than that of the medium-grained specimen.

(2) As for the mineral distribution and the number of natural microfractures in a fracture element, the internal heterogeneity affected the rock tensile strength. It was not difficult to speculate that the heterogeneity of detrital minerals distribution in a medium-grained conglomerate specimen was more obvious than that in a fine-grained conglomerate specimen. Meanwhile, there were many natural microfractures among gravels and cement in the specimen. The accumulation of the microfractures was close to the rock tensile strength and fracture propagation. Due to the large gravel size and a large amount of cement, the number of the natural microfracture would be more in medium-grained conglomerate specimens than that of fine-grained ones.

Therefore, as shown in Figure 4, for the fine-grained conglomerate specimen, when the initial fracture occurred, the fracture element at the front of the microfracture was several gravels and cement. However, for a medium-grained or a large gravel size conglomerate specimen, the fracture element might be only two gravels and cement.

The fracture element influenced the fracture behavior of a specimen, such as the tensile stiffness in a Brazilian splitting test. From a time scale, the fracture element occurred with the initiation of a microfracture and the propagation of the microfracture before they accumulated to be a macrofracture. The tensile stiffness of a specimen was represented by the slope of the loading curve in Figure 3. According to the difference of the line slope, the tensile stiffness at different loading periods was divided into three loading stages. That was the compressive stage ( $1^{\text {st }}$ stage), the elastic deformation stage ( $2^{\text {nd }}$ stage), and the plastic-unstable propagation stage $\left(3^{\text {rd }}\right.$ stage). The value of the tensile stiffness at each stage is shown in Figure 5. In the compressive stage, the larger the gravel size, the more obvious the stress concentration on the large-size gravel, so the tensile stiffness of the $6.0-20.0 \mathrm{~mm}$ specimen was the largest. In the elastic deformation stage, the specimen was well compacted. As the gravel size increased, the defects among the gravels gradually evolved, resulting in microdamage; thus tensile stiffness was reduced. During the plastic-unstable 


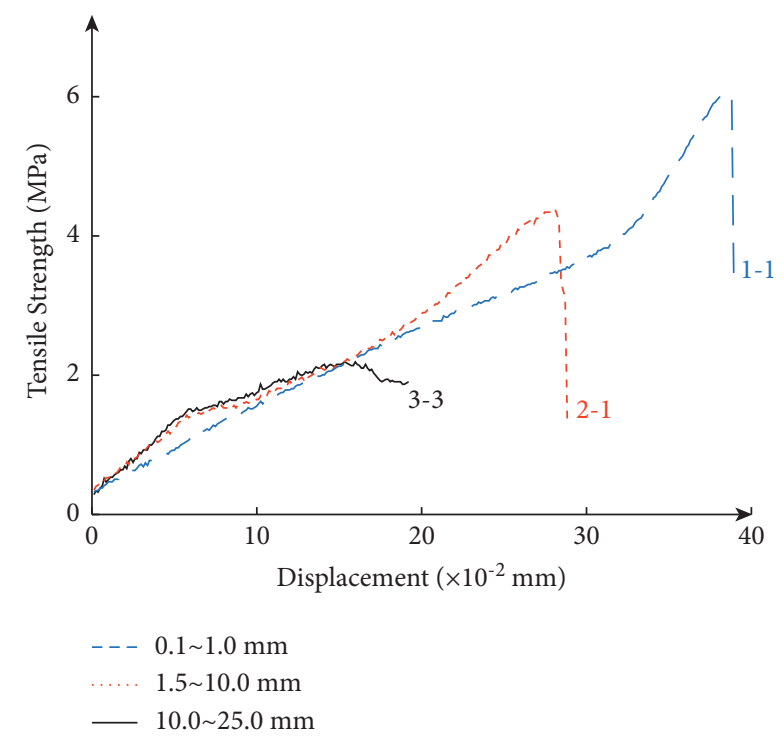

Figure 3: Central point tensile stress vs. displacement curve for specimens with different grain sizes.

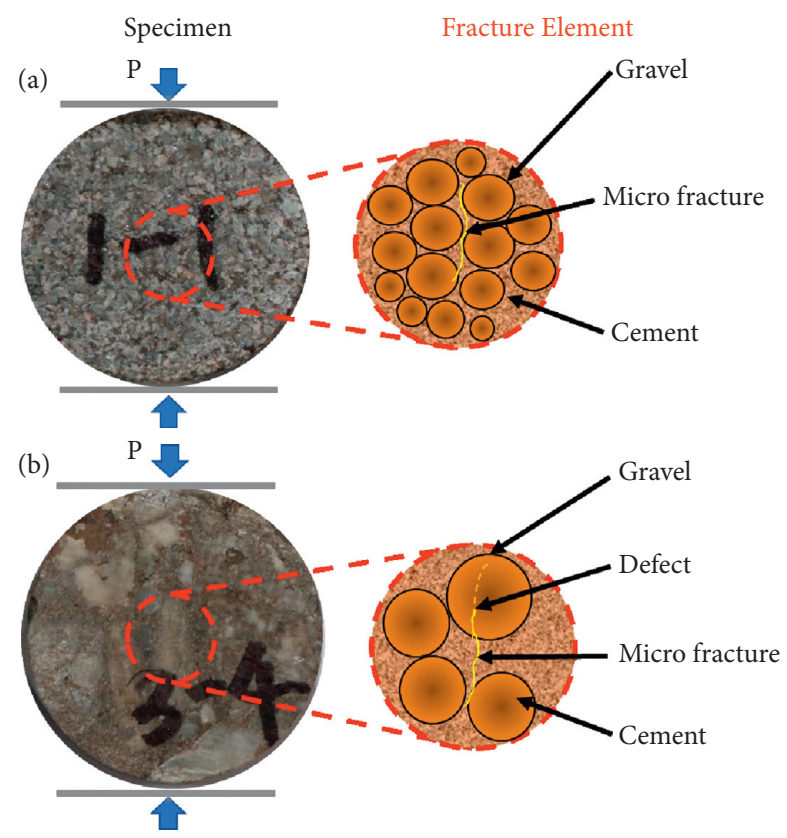

Figure 4: Fracture element of the conglomerate specimen: (a) finegrained; (b) medium-grained.

propagation stage, the damage accumulation in the medium-grained conglomerate was greater than that in the fine-grained conglomerate. So, the overall stiffness of the medium-grained conglomerate was the smallest, and fracture occurred under a low load.

When a defect occurred, the larger the gravel size was, the more obvious the stress concentration was, and the smaller the shielding effect at the front of the fracture [43] was; then it was easy to quickly accumulate to be a macrofracture. Unlike the medium-grained conglomerate specimen, due to the randomness of the gravel distribution, the shielding effect of the fracture front was more obvious

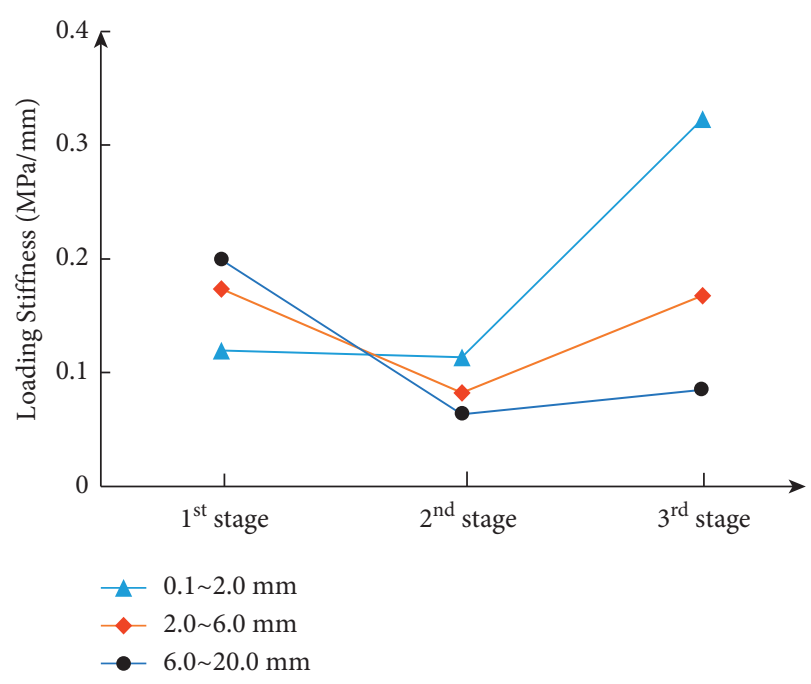

Figure 5: Loading stiffness for different stages.

when the microfractures were formed in the fine-grained conglomerate fracture element. The expansion of the microfractures needed to consider the corresponding selectivity, so it increased the tensile stiffness, which in turn increased the tensile strength.

3.2. Hydraulic Fractures Prone to Extend to the Large-Size Gravel Layer. To easily distinguish hydraulic fractures, a red tracer was added to the fracturing fluid during fracturing. Figure 6 shows the hydraulic fractures of ABA-type layered specimens. The layer to initiate the hydraulic fracture was selected at the fine-grained conglomerate layer. In the $1^{\#}$ specimen, the hydraulic fractures penetrated the entire specimen. In the $2^{\#}$ specimen, hydraulic fracture penetrated the fine-grained conglomerate layer firstly; then it extended to the medium-grained conglomerate layer.

The hydraulic fractures of the BAB-type layered specimens are shown in Figure 6. Hydraulic fractures of $3^{\#}$ and $4^{\#}$ specimens tended to a single-wing propagation. The undulation frequency of the hydraulic fracture surface was significantly smaller than that of the ABA-type layered specimens.

Figure 6 shows that the undulation frequency of the hydraulic fracture surface of the fine-grained conglomerate layer was high, which will affect the migration and placement of proppant [36]. The reasons for the high frequency of undulation were summarized as follows:

(i) The tensile strength of medium-grained conglomerate was low, and the probability of hydraulic fracture penetrating the gravel was high. During hydraulic fracturing, the hydraulic fractures might wind or penetrate the gravel. The undulation frequency of the hydraulic fracture surface was affected by the penetration ratio. When hydraulic fractures are winding gravel, the undulation frequency of the hydraulic fracture surface increased and swung, and the magnitude was near to the gravel size [36]. Although the size of medium gravel was larger than 


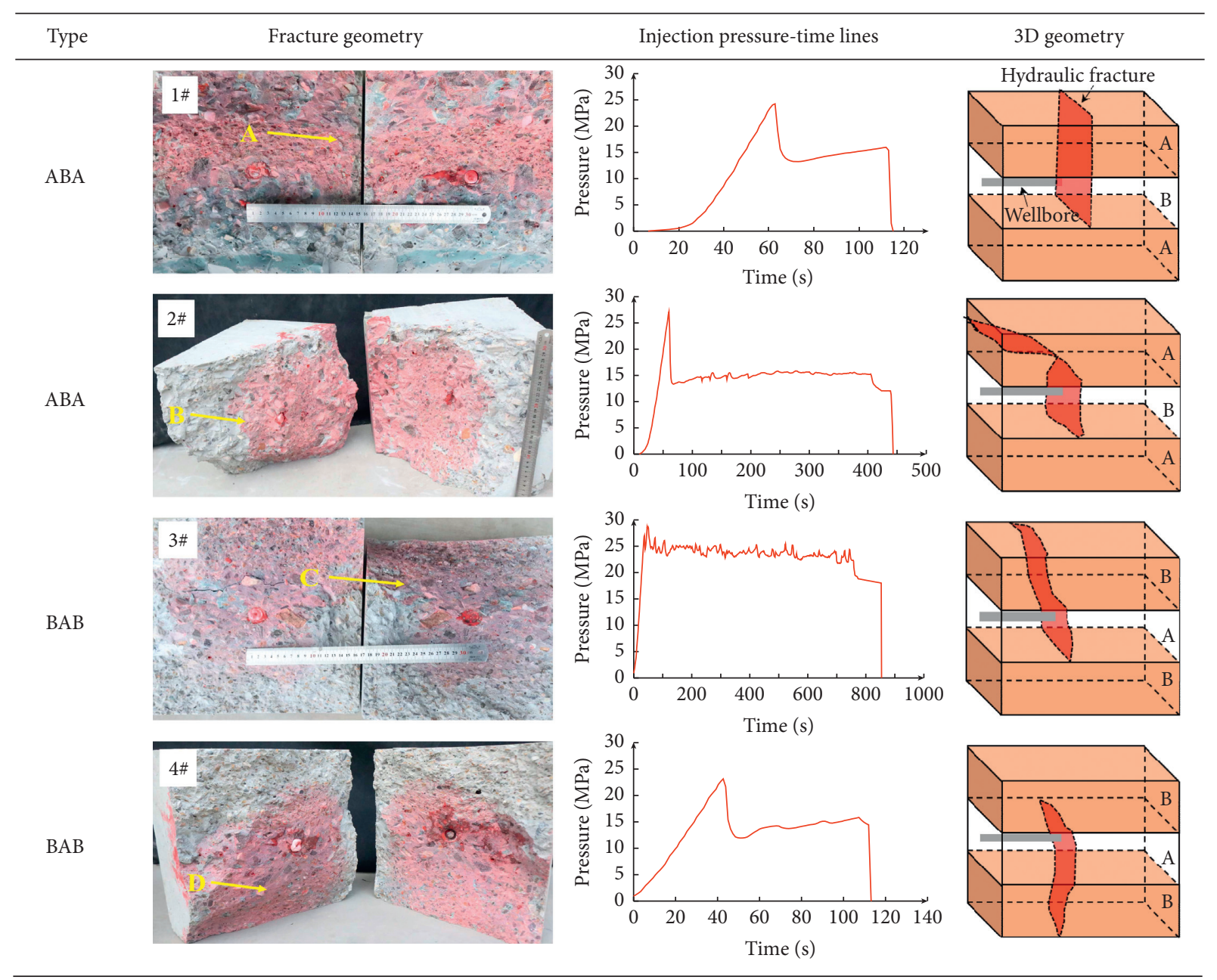

Figure 6: Hydraulic fractures and injection pressure-time lines of layered specimens.

that of fine size, due to the high rate of penetration in medium gravel, the frequency of fracture surface undulation was small.

(ii) From the perspective of rock mechanics, hydraulic fractures propagated step by step. That is, a fracture formed in multiple steps, and the difference in tensile strength affected the fracture propagation rate. The higher the tensile strength was, the more the energy was needed to accumulate, and the slower the fracture propagated. It was more prone for hydraulic fractures to wind the gravel. It led to an increase in the frequency of the fracture surface.

3.3. The Expansion Mode of Hydraulic Fractures at the Junction of Large and Small Gravels. The points of A/B/C/D in Figure 6 were the positions where hydraulic fractures deflected. They were located at the junction of fine-grained conglomerate and medium-grained conglomerate. The difference in the tensile strength of the layers limited the propagation of the hydraulic fractures. When the middle layer was the fine-grained conglomerate, the tensile strength in the middle layer was high. The hydraulic fracture was easy to propagate to a layer with low tensile strength, and double- wing propagation was easy to occur. At the junction of large and small gravels layers, it was easy for the hydraulic fracture to wind the gravel.

When the middle layer was a medium-grained conglomerate, hydraulic fracture firstly formed in this layer. Then, it extended to the fine-grained conglomerate layer. The hydraulic fracture was prone to extend in a layer with a lower tensile strength. As we all know, the fracture toughness and tensile strength of rock were positively correlated. That is to say, the fracture toughness for the conglomerate rock with a larger gravel size was higher than the smaller one. If the hydraulic fractures propagate to the side with larger size already, the rate of the stress intensity factor at this side reaching corresponding fracture toughness would be sooner than the other side; then hydraulic fracture was more prone to single-wing expansion. The deflection radius of the hydraulic fracture on the side of the fine-grained conglomerate was similar to the size of the fine-grained conglomerate gravel, and the frequency of fracture undulation was high.

3.4. Recommendations for Horizontal Wells Designing in Conglomerate Reservoirs. Due to the large heterogeneity of the mechanical properties of conglomerate reservoirs, 


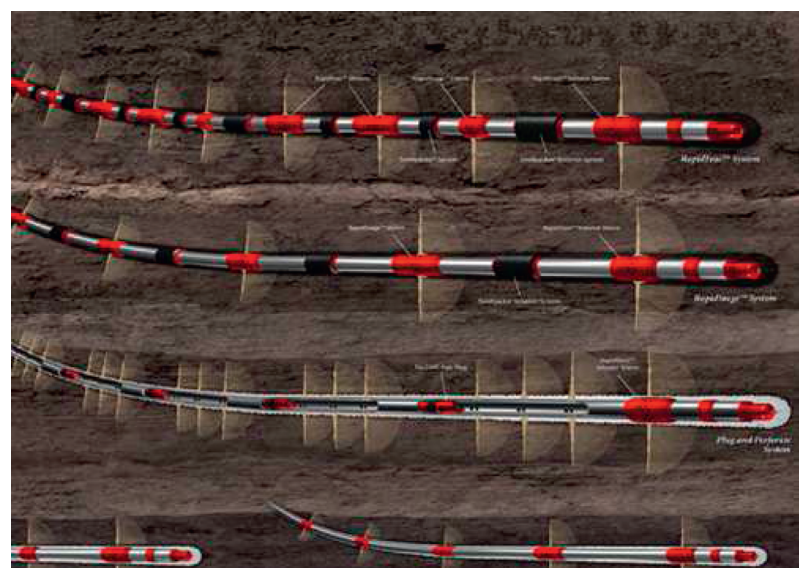

FIGURE 7: Schematic diagram of multilevel horizontal well for conglomerate formation in vertical direction.

horizontal wells were mostly used. The well was advisable to lay in the layers with large-size gravel. As shown in Figure 6, the hydraulic fracture surface at the mediumgrained conglomerate was relatively flat. The undulation frequency of hydraulic fractures initiating from the fine gravel layer was relatively high. Relatively flat fractures were significant to the migration and deployment of proppants. So, it was recommended to lay wells in a layer with large-size gravel.

As shown in Figure 7, multiple horizontal wells were suggested to be set along the vertical direction. Hydraulic fracturing experiments showed that fine-grain conglomerates limited the fracture height of hydraulic fractures. Therefore, when conglomerate reservoirs were thick $(>60.0 \mathrm{~m})$ or there were many layers of large and small size gravel, multiple horizontal wells were recommended to be used. The schematic diagram is shown in Figure 7. The mechanical properties of rocks were different in different oil fields. The microseismic technique can be used to test the high fracture pressure in fine-grained and medium-grained conglomerate reservoirs; then multiple horizontal wells based on this can be designed.

\section{Conclusions}

In this paper, the tensile strength of conglomerate specimens with different gravel sizes was obtained through the Brazilian split tests. Then, some true triaxial hydraulic fracturing experiments were conducted on the layered specimens with different gravel sizes. The mechanism of the influence of gravel size on hydraulic fracture was analyzed. A few conclusions are drawn as follows:

(i) The tensile strength of conglomerate rock decreased with the increase of the gravel size. The average tensile strength of the medium-grained conglomerate specimen was about $46.6 \%-68.4 \%$ of the finegrained conglomerate specimen.

(ii) The concept of conglomerate fracture element was proposed, and the influence mechanism of conglomerate size on the tensile strength of the conglomerate specimen was analyzed.

(iii) Due to the difference of the tensile strength with various gravel sizes, hydraulic fractures were more likely to extend to the layer with a larger gravel size. The smaller the gravel size, the lower the penetration possibility.

In this paper, only manual hydraulic specimens were used for hydraulic fracturing experiments. Natural layered conglomerate rocks can be used for further physical simulation experiments. It is helpful for understanding the hydraulic fracture propagation under different gravel sizes in conglomerate reservoirs, and it can provide a reference for the well distribution and fracturing design.

\section{Data Availability}

The data used to support the findings of this study are available from the corresponding author upon request.

\section{Conflicts of Interest}

The authors declare that they have no conflicts of interest.

\section{Acknowledgments}

This work was financially supported by the National Science and Technology Major Projects of China (Grant no. 2016ZX05006-005).

\section{References}

[1] M. Altwaijri, Z. Xia, W. Yu et al., "Numerical study of complex fracture geometry effect on two-phase performance of shalegas wells using the fast EDFM method," Journal of Petroleum Science and Engineering, vol. 164, pp. 603-622, 2018.

[2] U. Aybar, M. O. Eshkalak, K. Sepehrnoori, and T. W. Patzek, "The effect of natural fracture's closure on long-term gas production from unconventional resources," Journal of Natural Gas Science and Engineering, vol. 21, pp. 1205-1213, 2014.

[3] R. Barati and J. Liang, "A review of fracturing fluid systems used for hydraulic fracturing of oil and gas wells," Journal of Applied Polymer Science, vol. 131, no. 16, 2014.

[4] E. Detournay, "Mechanics of hydraulic fractures," Annual Review of Fluid Mechanics, vol. 48, no. 1, pp. 311-339, 2016.

[5] T. Fan, G. Zhang, and J. Cui, "The impact of cleats on hydraulic fracture initiation and propagation in coal seams," Petroleum Science, vol. 11, no. 4, pp. 532-539, 2014.

[6] L. Chen, Z. Jiang, Q. Liu et al., "Mechanism of shale gas occurrence: insights from comparative study on pore structures of marine and lacustrine shales," Marine and Petroleum Geology, vol. 104, pp. 200-216, 2019.

[7] H. Huang, R. Li, Z. Jiang, J. Li, and L. Chen, "Investigation of variation in shale gas adsorption capacity with burial depth: insights from the adsorption potential theory," Journal of Natural Gas Science and Engineering, vol. 73, Article ID 103043, 2020.

[8] H. Huang, R. Li, and W. Chen, "Revisiting movable fluid space in tight fine-grained reservoirs: a case study from Shahejie 
shale in the Bohai Bay Basin, NE China," Journal of Petroleum Science and Engineering, vol. 207, Article ID 109170, 2021.

[9] L. Chen, L. Zuo, Z. Jiang et al., "Mechanisms of shale gas adsorption: evidence from thermodynamics and kinetics study of methane adsorption on shale," Chemical Engineering Journal, vol. 361, pp. 559-570, 2019.

[10] H. Huang, R. Li, and F. Xiong, "A method to probe the porethroat structure of tight reservoirs based on low field NMR: insights from a cylindrical pore model," Marine and Petroleum Geology, vol. 117, Article ID 104344, 2020.

[11] L. Chen, K. Liu, S. Jiang, H. Huang, J. Tan, and L. Zuo, "Effect of adsorbed phase density on the correction of methane excess adsorption to absolute adsorption in shale," Chemical Engineering Journal, vol. 420, Article ID 127678, 2021.

[12] X. Feng and S. Yu, Damage Micromechanics of Quasi-Brittle Materials, pp. 141-158, Higher Education Press, Beijing, China, 2002.

[13] G. M. Friedman, "Classification of sediments and sedimentary rocks," in Sedimentology, Encyclopedia of Earth Science, pp. 202-205, Springer, Berlin, Germany, 1987.

[14] B. Hou, C. Zeng, D. Chen, M. Fan, and M. Chen, "Prediction of wellbore stability in conglomerate formation using discrete element method," Arabian Journal for Science and Engineering, vol. 42, no. 4, pp. 1609-1619, 2017.

[15] W. Ji, F. Hao, H.-M. Schulz, Y. Song, and J. Tian, “The architecture of organic matter and its pores in highly mature gas shales of the Lower Silurian Longmaxi Formation in the Upper Yangtze Platform, south China," AAPG Bulletin, vol. 103, no. 12, pp. 2909-2942, 2019.

[16] K.-Y. Kim, J. Oh, W. S. Han, K. G. Park, Y. J. Shinn, and E. Park, "Two-phase flow visualization under reservoir conditions for highly heterogeneous conglomerate rock: a corescale study for geologic carbon storage," Scientific Reports, vol. 8, no. 1, p. 4869, 2018.

[17] J. E. Lindqvist, U. Åkesson, and K. Malaga, "Microstructure and functional properties of rock materials," Materials Characterization, vol. 58, no. 11-12, pp. 1183-1188, 2007.

[18] X. Liu, Z. Qu, T. Guo, and Y. Sun, "Numerical simulation of artificial fracture propagation in shale gas reservoirs based on FPS-cohesive finite element method," Geofluids, vol. 2019, Article ID 9402392, 16 pages, 2019.

[19] J. T. Fredrich, B. Evans, and T.-F. Wong, "Effect of grain size on brittle and semibrittle strength: implications for micromechanical modelling of failure in compression," Journal of Geophysical Research, vol. 95, no. B7, pp. 10907-10920, 1990.

[20] R. H. H. Hugman and M. Friedman, "Effects of texture and composition on mechanical behavior of experimentally deformed carbonate rocks," AAPG Bulletin, vol. 63, no. 9, pp. $1478-1489$.

[21] W. A. Olsson, "Grain size dependence of yield stress in marble," Journal of Geophysical Research, vol. 79, no. 32, pp. 4859-4862, 1974.

[22] Q. Yu, W. Zhu, P. G. Ranjith, and S. Shao, "Numerical simulation and interpretation of the grain size effect on rock strength," Geomechanics and Geophysics for Geo-Energy and Geo-Resources, vol. 4, no. 2, pp. 157-173, 2018.

[23] A. Lakirouhani, F. Asemi, A. Zohdi, J. Medzvieckas, and R. Kliukas, "Physical parameters, tensile and compressive strength of Dolomite rock samples: influence of grain size," Journal of Civil Engineering and Management, vol. 26, no. 8, pp. 789-799, 2020.

[24] R. Přikryl, "Some microstructural aspects of strength variation in rocks," International Journal of Rock Mechanics and Mining Sciences, vol. 38, no. 5, pp. 671-682, 2001.
[25] O. K. Mahabadi, B. S. A. Tatone, and G. Grasselli, "Influence of microscale heterogeneity and microstructure on the tensile behavior of crystalline rocks," Journal of Geophysical Research: Solid Earth, vol. 119, no. 7, pp. 5324-5341, 2014.

[26] Z. Liu, Y. Li, J. Lv, B. Li, and Y. Chen, "Optimization of polymer flooding design in conglomerate reservoirs," Journal of Petroleum Science and Engineering, vol. 152, pp. 267-274, 2017.

[27] G. W. Ma, X. J. Wang, and F. Ren, "Numerical simulation of compressive failure of heterogeneous rock-like materials using SPH method," International Journal of Rock Mechanics and Mining Sciences, vol. 48, no. 3, pp. 353-363, 2011.

[28] O. Mahmic, H. Dypvik, and E. Hammer, "Diagenetic influence on reservoir quality evolution, examples from Triassic conglomerates/arenites in the Edvard Grieg field, Norwegian North Sea," Marine and Petroleum Geology, vol. 93, pp. 247-271, 2018.

[29] M. Meng, H. Ge, Y. Shen, L. Li, T. Tian, and J. Chao, “The effect of clay-swelling induced cracks on imbibition behavior of marine shale reservoirs," Journal of Natural Gas Science and Engineering, vol. 83, Article ID 103525, 2020.

[30] Y. Nie, G. Zhang, Y. Xing, and S. Li, "Influence of water-oil saturation on the fracture process zone: a modified DugdaleBarenblatt model," Energies, vol. 11, no. 11, Article ID 2882, 2018.

[31] J. Suchorzewski, J. Tejchman, and M. Nitka, "Experimental and numerical investigations of concrete behaviour at mesolevel during quasi-static splitting tension," Theoretical and Applied Fracture Mechanics, vol. 96, pp. 720-739, 2018.

[32] J. Peng, L. N. Y. Wong, and C. I. Teh, "Influence of grain size heterogeneity on strength and microcracking behavior of crystalline rocks," Journal of Geophysical Research: Solid Earth, vol. 122, no. 2, pp. 1054-1073, 2017.

[33] D. O. Potyondy and P. A. Cundall, "A bonded-particle model for rock," International Journal of Rock Mechanics and Mining Sciences, vol. 41, no. 8, pp. 1329-1364, 2004.

[34] S.-Q. Yang and Y.-H. Huang, "Particle flow study on strength and meso-mechanism of Brazilian splitting test for jointed rock mass," Acta Mechanica Sinica, vol. 30, no. 4, pp. 547-558, 2014.

[35] V. Pandurangan, A. Peirce, Z. R. Chen, and Z. R. Jeffrey, "Tiltmeter mapping of measured nonsymmetric hydraulicfracture growth in a conglomerate/sandstone formation using the implicit level-set algorithm and the extended Kalman filter," SPE Journal, vol. 23, no. 1, pp. 172-185, 2018.

[36] Y. Nie, G. Nie, J. Wen, S. Li, and D. Zhou, "Cyclic injection to reduce hydraulic fracture roughness of glutenite reservoirs," International Journal of Rock Mechanics and Mining Sciences, vol. 42, Article ID 10470, 2021.

[37] Z. Rui, T. Guo, Q. Feng, Z. Qu, N. Qi, and F. Gong, "Influence of gravel on the propagation pattern of hydraulic fracture in the glutenite reservoir," Journal of Petroleum Science and Engineering, vol. 165, pp. 627-639, 2018.

[38] H. Shimizu, S. Murata, and T. Ishida, "The distinct element analysis for hydraulic fracturing in hard rock considering fluid viscosity and particle size distribution," International Journal of Rock Mechanics and Mining Sciences, vol. 48, no. 5, pp. 712-727, 2011.

[39] H. Shin and J. C. Santamarina, "Fluid-driven fractures in uncemented sediments: underlying gravel-level processes," Earth and Planetary Science Letters, vol. 299, no. 1, pp. 180189, 2010.

[40] T. H. Yang, L. G. Tham, C. A. Tang, Z. Z. Liang, and Y. Tsui, "Influence of heterogeneity of mechanical properties on 
hydraulic fracturing in permeable rocks," Rock Mechanics and Rock Engineering, vol. 37, no. 4, pp. 251-275, 2004.

[41] G. Zhang and M. Chen, "Dynamic fracture propagation in hydraulic re-fracturing," Journal of Petroleum Science and Engineering, vol. 70, no. 3, pp. 266-272, 2010.

[42] L. Li, Q. Meng, S. Wang, G. Li, and C. Tang, "A numerical investigation of the hydraulic fracturing behaviour of conglomerate in Glutenite formation," Acta Geotechnica, vol. 8, no. 6, pp. 597-618, 2013.

[43] X. Liu, S. Wang, S. Wang, and E. Wang, "Fluid-driven fractures in granular materials," Bulletin of Engineering Geology and the Environment, vol. 74, no. 2, pp. 621-636, 2015.

[44] K. Duan, C. Y. Kwok, W. Wu, and L. Jing, "DEM modeling of hydraulic fracturing in permeable rock: influence of viscosity, injection rate and in situ states," Acta Geotechnica, vol. 13, no. 5, pp. 1187-1202, 2018.

[45] X. Ma, Y. Zou, N. Li, M. Chen, Y. Zhang, and Z. Liu, "Experimental study on the mechanism of hydraulic fracture growth in a glutenite reservoir," Journal of Structural Geology, vol. 97, pp. 37-47, 2017.

[46] L. N. Y. Wong, J. Peng, and C. I. Teh, "Numerical investigation of mineralogical composition effect on strength and microcracking behavior of crystalline rocks," Journal of Natural Gas Science and Engineering, vol. 53, pp. 191-203, 2018.

[47] F. Xiong, Z. Jiang, H. Huang, M. Wen, and J. Moortgat, "Mineralogy and gas content of upper paleozoic shanxi and benxi shale formations in the ordos basin," Energy \& Fuels, vol. 33, no. 2, pp. 1061-1068, 2019.

[48] W.-J. Xu, Z.-Q. Yue, and R.-L. Hu, "Study on the mesostructure and mesomechanical characteristics of the soil-rock mixture using digital image processing based finite element method," International Journal of Rock Mechanics and Mining Sciences, vol. 45, no. 5, pp. 749-762, 2008.

[49] S.-Q. Yang and H.-W. Jing, "Strength failure and crack coalescence behavior of brittle sandstone samples containing a single fissure under uniaxial compression," International Journal of Fracture, vol. 168, no. 2, pp. 227-250, 2011.

[50] K. Zhang, Y. Song, S. Jiang et al., "Mechanism analysis of organic matter enrichment in different sedimentary backgrounds: a case study of the Lower Cambrian and the Upper Ordovician-Lower Silurian, in Yangtze region," Marine and Petroleum Geology, vol. 99, pp. 488-497, 2019.

[51] S.-C. Zhang, X. Lei, Y.-S. Zhou, and G.-Q. Xu, "Numerical simulation of hydraulic fracture propagation in tight oil reservoirs by volumetric fracturing," Petroleum Science, vol. 12, no. 4, pp. 674-682, 2015.

[52] Z. Zhao, S. Xu, X. Jiang et al., "Deep strata geologic structure and tight sandy conglomerate gas exploration in Songliao Basin, East China," Petroleum Exploration and Development, vol. 43, no. 1, pp. 13-25, 2016.

[53] Y. Zhou, S. Wu, Z. Li et al., "Multifractal study of threedimensional pore structure of sand-conglomerate reservoir based on CT images," Energy \& Fuels, vol. 32, no. 4, pp. 4797-4807, 2018.

[54] ISRM, "Suggested methods for determining tensile strength of rock materials," International Journal of Rock Mechanics and Mining Sciences Geomechanics Abstract, vol. 15, no. 3, pp. 99-103, 1978.

[55] Y. X. Zhou, K. Xia, X. B. Li et al., "Suggested methods for determining the dynamic strength parameters and Mode-I fracture toughness of rock materials," International Journal of Rock Mechanics and Mining Sciences, vol. 49, pp. 105-112, 2012.
[56] M. K. Hubbert, "Darcy's law and the field equations of the flow of underground fluids," Transactions of the AIME, vol. 207, no. 01, pp. 222-239, 1956.

[57] J. Bear, Dynamics of Fluids in Porous Media, pp. 15-26, Elsevier Science, New York, NY, USA, 1972.

[58] J. Bear and Y. Bachmat, Introduction to Modeling of Transport Phenomena in Porous Media, pp. 16-28, Kluwer, Norwell, Mass, 1990.

[59] G. O. Brown, H. T. Hsieh, and D. A. Lucero, "Evaluation of laboratory dolomite core sample size using representative elementary volume concepts," Water Resources Research, vol. 36, no. 5, pp. 1199-1207, 2000. 